\title{
Propagation of Reaction Between Bubbles with a Gas Burning in a Fluidised Bed
}

\author{
Jerzy Baron • Elżbieta Maria Bulewicz • \\ Jadwiga Zabagło • Witold Żukowski
}

Received: 9 September 2010 / Accepted: 21 July 2011 / Published online: 11 August 2011

(C) The Author(s) 2011. This article is published with open access at Springerlink.com

\begin{abstract}
A bubbling fluidised bed reactor has been used for investigating how combustion propagates between bubbles of premixed fuel + air, rising from the distributor towards the surface. Earlier work has shown that when the temperature of the sand gradually rises, the gases first burn in flames above the bed, regime A, then combustion moves under its surface, to occur in bubbles travelling up the bed, under regime B. Above a certain temperature, characteristic of the gas mixture composition, combustion descends towards the bottom of the bed. Ignition then occurs in small bubbles near the distributor, under the stable regime $\mathrm{C}$. The kinetic model, used to calculate the delay for thermal ignition inside gas bubbles rising through the bed, gives correct predictions for regimes $\mathrm{A}$ and $\mathrm{C}$ but not for $\mathrm{B}$. Under regime $\mathrm{B}$, bubbles of the mixture begin to ignite under the bed's surface while their residence time in the bed is remains shorter than the delay times for thermal ignition derived from the kinetic model. As the temperature rises, the ignition delay rapidly decreases, and regime $\mathrm{C}$ is reached, in accordance with the model. In this work attention was focused on regime B. A laboratory reactor of quartz glass was used, with a bed of quartz sand. Fast video recording was employed to capture ignition phenomena as the bed's temperature was raised or lowered. Records of freeboard concentrations of $\mathrm{O}_{2}, \mathrm{CO}$ and of total hydrocarbons, VOCs, were obtained, confirming the specific aerodynamic and chemical character of regime B. It has been shown that combustion spreads from the surface to bubbles near the bed's surface and then to other bubbles close by. Such transfer of the reaction stabilizes combustion inside the bed, at temperatures appreciably lower than that for the thermal ignition of the mixture, given by the kinetic model. This is consistent
\end{abstract}

Electronic supplementary material The online version of this article (doi:10.1007/s10494-011-9362-z) contains supplementary material, which is available to authorized users.

J. Baron $(\varangle)$ · E. M. Bulewicz · J. Zabagło · W. Żukowski

Cracow University of Technology, Cracow, Poland

e-mail: baron@pk.edu.pl 
with earlier findings, which have shown that the combustion of gaseous mixtures in bubbling fluidised beds is controlled by gas phase processes, as in flames.

Keywords Fluidised bed • Gas combustion • Fast video recording • Organisation of combustion process

\section{Introduction}

Combustion of gases in a bubbling fluidised bed of inert particles, e.g. quartz sand, is associated with physical phenomena. The acoustic effects are striking; light emission is less obvious. The effects change with temperature and carry information about the process. At first the acoustic effects were ascribed to explosive ignition of gases in bubbles leaving the bed $[1,2]$. For methane and propane it was shown that, at incipient fluidisation, reaction in the bed was possible only above $915^{\circ} \mathrm{C}$ and $835^{\circ} \mathrm{C}$ respectively [3]. At higher fluidisation velocities, with the bed at $<770-800^{\circ} \mathrm{C}$, propane burned in the freeboard, just above the bed surface; up to $900^{\circ} \mathrm{C}$, the process took place inside bubbles, once these had reached a critical size. If the bed was hotter still, $>900^{\circ} \mathrm{C}$, reaction occurred in bubbles just above the distributor $[4,5]$. The acoustic effects were strongest at about $820^{\circ} \mathrm{C}$ [6], i.e. when rising bubbles ignited inside the bed, away from the distributor. The combustion of premixed gases was thus intermittent, and the sound intensity was linked to the size of the exploding bubbles. For propane-butane mixtures in a bed of sand the intensity of acoustic signals gradually fell as the temperature rose from $820^{\circ} \mathrm{C}$ to $930^{\circ} \mathrm{C}$ [7]. Series of high amplitude signals were isolated and ascribed to explosions propagating from one bubble to another. Mathematical analysis of the signals showed that up to $\sim 890^{\circ} \mathrm{C}$ such propagation was quite frequent, but increasingly rare at higher temperatures [8]. Pressure pulsations registered as signal intensity v. time above the bed (in the freeboard) and under it (in the plenum chamber) came from explosive ignition of premixed gases in bubbles passing through the bed. Most of the strong, high frequency signals recorded above the bed could be matched with those obtained from below, which indicated that they came from the same source inside the bed [9].

For methane-air mixtures the sounds were loudest at $\sim 890^{\circ} \mathrm{C}$, and signal amplitudes were higher above the bed, but as the temperature rose, they fell more quickly than the amplitudes of signals received below the bed. Above $\sim 1000^{\circ} \mathrm{C}$, these signals grew stronger, consistent with bubbles igniting close to the distributor, not with the absence of explosive combustion.

Combustion of gaseous mixtures in bubbling fluidised beds is also accompanied by light emission. The quartz sand is opaque and behaves like a grey body, but photographs taken through the walls of the quartz reactor demonstrated that light flashes occur in the bed, with strong components in the blue and green, superimposed on grey-body emission from the sand, (mainly orange to red) [10]. Blue and green chemiluminescent emission in the flashes is characteristic of all hydrocarbon flames and is particularly strong with premixed gases [11].

Mixing of solids in a bubbling fluidised bed is intense, but when the bed temperature was measured using a set of thermocouples mounted at different heights above the distributor, the vertical temperature passed through a maximum. The position of the maximum indicated where combustion occurred and most heat was 
evolved. Below a certain mean temperature of the sand, the temperature maximum lay in the freeboard; above this temperature it moved into the bed. Records from individual thermocouples showed local temperature fluctuations, strongest near the temperature maximum, confirming that the heat came from discrete events above or below the bed's surface [12-14]. Local temperatures near the quartz walls of the reactor were also measured by an optical method, with much better resolution (in space and time) and with no sensors in the bed. Vertical and horizontal temperature profiles for the visually accessible regions of the bed were constructed and locally hotter sand was linked to explosions in bubbles [15]. On the basis of the observations, three combustion regimes were distinguished: A-the gases burning above the distributor, $\mathrm{B}$ - combustion inside the bed, with prominent acoustic effects and $\mathrm{C}$ reaction low down in the bed, with much less sound.

Detailed kinetic models for the combustion of individual fuels in a bubbling fluidised bed give the ignition delay for the thermal ignition of the gas mixture inside a bubble rising through the bed [12-14]. With the induction period longer than the time a bubble takes to pass through the bed, the gases should burn in the freeboard, regime A. With rising temperature, the ignition delay decreases; when it becomes less than the time a bubble takes to reach the bed's surface, the reaction should move into the bed, then down to the distributor, regime $\mathrm{C}$. There should be only one transition temperature, between regimes $\mathrm{A}$ and $\mathrm{C}$. The model was fully consistent with the experimental vertical temperature profiles and other observations only when the mean temperature of the bed was either relatively low, on the low temperature side of regime $\mathrm{A}$, or when it was high, regime $\mathrm{C}$. For regime $\mathrm{C}$ the height above the distributor at which ignition occurred in gas bubbles was predicted accurately. Regime $\mathrm{B}$ should be absent, the observed transition from regime A to B occurs well before regime $\mathrm{C}$ is reached, i.e. regime $\mathrm{B}$ appears at the expense of regime $\mathrm{A}$ and marks the region of "premature" (with respect to the calculated ignition delay) ignition of the gases inside the bed. With $40 \%$ air excess the transition temperatures for methane and ethane were, respectively: (a) from regime A to B: 550 and $525^{\circ} \mathrm{C}$; (b) from regime $\mathrm{B}$ to $\mathrm{C}: 860$ and $808^{\circ} \mathrm{C}[12,13]$.

Two transitions, when combustion moves just below the bed's surface and when it settles at the distributor were also mentioned in work on propane-air mixtures burning in an externally heated fluidised bed, with much slower fluidisation [16].

The observations summarised above indicated that under regime A the bed acts as a secondary, undulating distributor, the flames resemble those on burners and are hardly affected by fluidisation. Under regimes B and C, with intermittent explosive reaction inside bubbles moving up the bed, the process differs from those on burners, in stationary catalytic beds, or during fluidised bed combustion of solid fuels. The specific character of "premature" ignition in bubbles rising up the bed under regime B needed accounting for.

The aim of the present work was to examine and elucidate the physicochemical phenomena occurring under regime B, at intermediate temperatures. "Looking inside the bed" might be helpful and the technique of magnetic resonance imaging may eventually prove very useful, but so far it has been employed to study fluidisation, rather than combustion in fluidised beds [17-19]. Optical recording is much simpler and suitable video cameras are readily available. Observations in the visible and near infra red, through the quartz walls of a laboratory reactor, can yield much useful information (subject to limitations due to radiation from the reactor 
walls) $[10,15]$. A fast video camera was used to record images of the phenomena observed when propane-air was burned in a bubbling fluidised bed of quartz sand. The concentrations of selected components of the gases in the freeboard were also monitored. The results have been used to show that under regime $\mathrm{B}$ the premature ignition is due to the transfer of chemical reaction from surface flames to bubbles underneath or, deeper down in the bed, between neighbouring bubbles. The analytical results emphasised the "anomalous" character of regime B.

\section{Experimental}

Propane-air was burned in a laboratory bubbling fluidised bed reactor, made of a $400 \mathrm{~mm}$ long section of a quartz tube, $96 \mathrm{~mm}$ i.d., resting on a flat distributor of $1 \mathrm{~mm}$ thick CrNi steel plate, with $62,500 / \mathrm{m}^{2}$ uniformly distributed $0.6 \mathrm{~mm}$ holes. A schematic of the reactor is given in Fig. 1. The bed material was quartz sand of particle size $0.385-0.43 \mathrm{~mm}$. Constant molar streams of air (40\% excess; constant flow rate $1.66 \mathrm{dm}^{3} / \mathrm{s}$ at ambient temperature) and propane (technical grade) were mixed under the distributor, before entering the bed. Fluidisation was fast, $\mathrm{U} / \mathrm{U}_{\mathrm{mf}}=$ 10.7 at $600^{\circ} \mathrm{C}, 12.7$ at $700^{\circ} \mathrm{C}$ and 15.5 at $830^{\circ} \mathrm{C}$. The value of $\mathrm{U}_{\mathrm{mf}}$ was calculated from

Fig. 1 The laboratory fluidised bed reactor-schematic. 1 Supply of propane-air mixture, 2

Plenum chamber, 3

Distributor, 4 Set of thermocouples, 5 Reflective, thermally insulating, movable shield, 6 Quartz tube

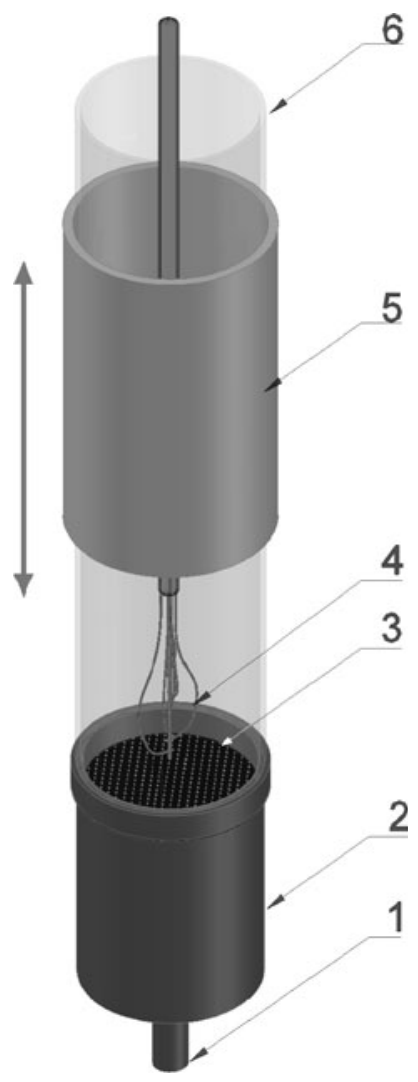


the equation of Wen and $\mathrm{Yu}$ [20]. A pilot flame, mounted in the freeboard, was used to ignite the mixture. The temperature distribution along the axis of the reactor was monitored using set of seven bare thermocouples ( $\mathrm{Ni}-\mathrm{CrNi}, 1.0 \mathrm{~mm}$ in diameter), mounted vertically above one another, 12, 20, 29, 40, 50, 60, and $70 \mathrm{~mm}$ above the distributor and numbered 2 to 8 , for consistency with earlier work [12-14]. There was no external heating, all the heat came from the reaction itself, but the reactor was surrounded by a cylindrical, concentric, reflective and thermally insulating shield. The reactor temperature was controlled by changing the heat losses-the shield could be lowered to reduce or raised to increase them, with additional convective cooling, if necessary.

A digital video HD camera, with fast recording function, was used to obtain optical images. Recordings lasted up to $10 \mathrm{~s}$, with frames taken at $4 \mathrm{~ms}$ intervals. The resolving power was $448 \times 336$ square pixels. The camera was mounted with its optical axis horizontal, so that both the fluidised bed and the freeboard were within the rectangular field of view (its longer side horizontal). The producer's digital recording system conformed to the H.264 standard, with MP4 film files. Compared with the standard (progressive mode) in digital TV, with this system the number of full colour frames obtained over a time interval is multiplied by 10 and $10 \mathrm{~s}$ recordings could be reproduced at reduced speed, to take $100 \mathrm{~s}$ at standard $25 \mathrm{fps}$, to capture features of very fast events that might otherwise be missed.

Total hydrocarbons were assessed using a FID instrument, JUM Model 3-200 m. For the concentrations of $\mathrm{O}_{2}$ and $\mathrm{CO}$ an electrochemical analyser, ECOM-SG Plus, was employed. The whole apparatus and the analytical methods have been described in detail earlier [21].

\section{Results and Discussion}

\subsection{The basic experimental procedure}

In a typical run, the mean temperature in of the fluidised bed was raised to about $950-1000^{\circ} \mathrm{C}$, lowered to $\sim 600^{\circ} \mathrm{C}$ and then the reactor was taken through one or more such cycles. Observations began at room temperature, with $300 \mathrm{~g}$ of quartz sand in the reactor, up to a height of $\sim 30 \mathrm{~mm}$ and three thermocouples immersed in it. The air and propane supplies were then turned on, to start fluidising the sand. The premixed gases ignited when they reached the pilot flame. After ignition the pilot flame was put out and the gases burned above the bed. This progressively heated the sand below, which then began preheating the gases inside the bubbles before they reached the surface.

As shown in Fig. 2a as the temperature rose, fluidisation became more vigorous and the bed expanded, engulfing successive thermocouples. Before ignition only thermocouples tc-2, tc-3 and tc- 4 were in the bed, then the dynamic height of the bed rose from $\sim 30 \mathrm{~mm}$ and to $>80 \mathrm{~mm}$ when the mean temperature reached $\sim 900^{\circ} \mathrm{C}$. The mean temperature was taken as the arithmetic mean of the results obtained from thermocouples tc-2-tc-5 (all inside the bed $<300 \mathrm{~s}$ after ignition. With tc6 , tc-7 and tc- 8 still above the bed, temperature differences between the top and bottom ones were large. As the process moved into the bed, the traces from the top and bottom thermocouples intersected and maximum temperature differences fell 


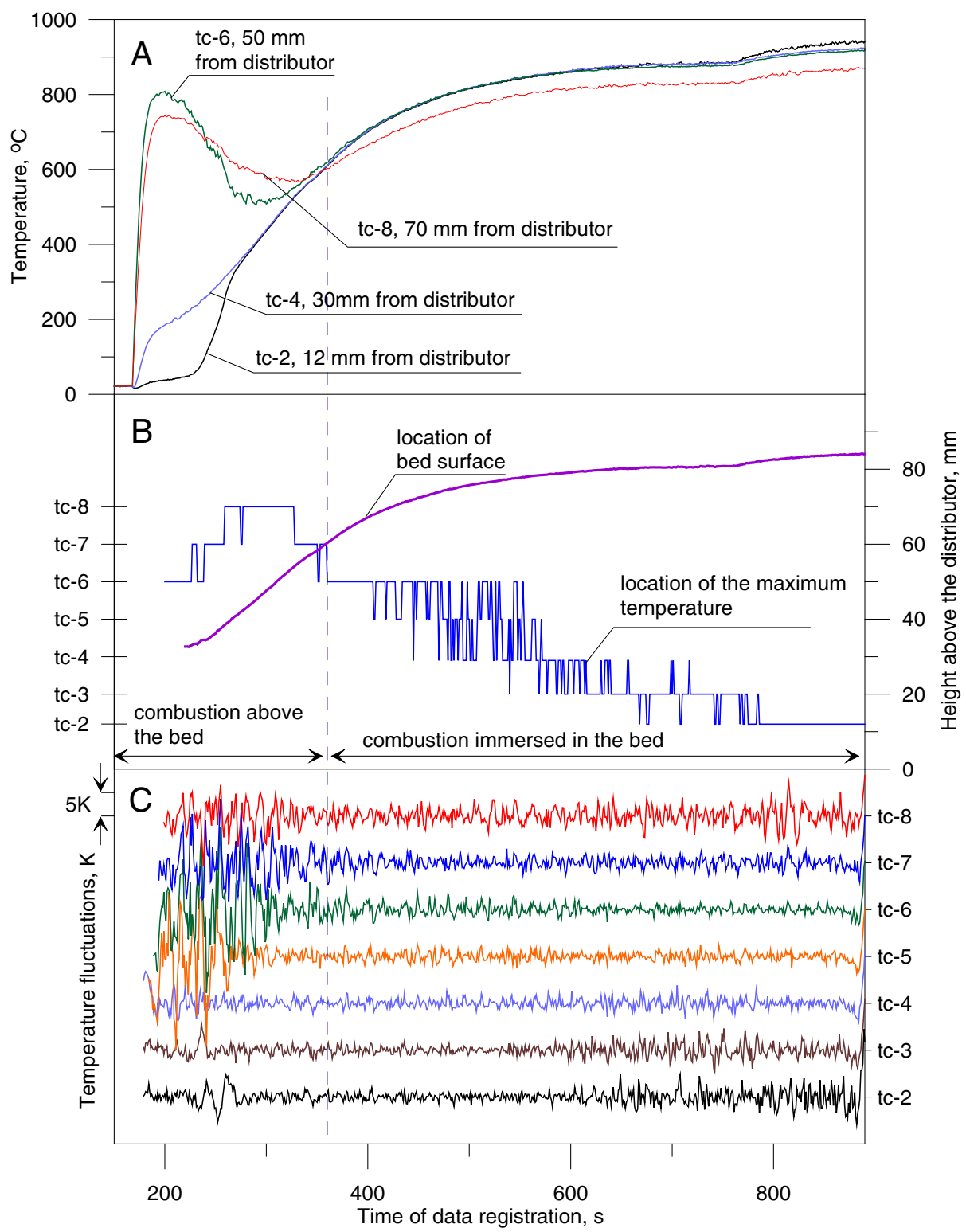

Fig. 2 Measured quantities and time from the start of the experiment. a Temperatures at different heights above the distributor. b Height of the bed and the location of the temperature maximum. c Temperature fluctuations at different heights in the combustor

$<100^{\circ} \mathrm{C}$. Figure $2 \mathrm{~b}$, based on records from all the thermocouples, gives the height above the distributor for the thermocouple which gave the highest temperature at each stage in the run. The observed mean dynamic position of the bed's surface is also shown. Over the first phase of the experiment the temperature maximum lay 
above the bed, but then moved under its surface and as the mean temperature rose further, descended towards the distributor.

Fluctuations in signals from individual thermocouples are shown in Fig. 2c. The signals were recorded at $0.005 \mathrm{~s}$ intervals, with superposition of components due to random, local exothermic processes near the thermocouples and those attributable to intrinsic noise from the recording system. To facilitate both qualitative and statistical analysis of the signals, mathematical procedures were employed to remove the noise component. Table 1 gives the variance of temperature fluctuations near the thermocouples, over selected ranges of the mean temperature. Over the first 300$360 \mathrm{~s}$ the fluctuations were strongest at the four top thermocouples, due to heating of the sand in the bed by flames over the bed's surface and intermittent cooling by contact with cooler sand particles thrown into the freeboard. The descent of the sand heated above caused the fluctuations lower down in the bed, at tc- 2 , tc- 3 and tc- 4 . After $\sim 360 \mathrm{~s}$ from ignition, the dynamic height of the bed reached $\sim 60 \mathrm{~mm}$ and the mean temperature $\sim 600{ }^{\circ} \mathrm{C}$, with differences between the readings from different thermocouples down to $20-30^{\circ} \mathrm{C}$. During the rest of the run the top thermocouple, tc-8, at the lowest mean temperature, with medium fluctuations, was near the rapidly undulating surface of the dynamic bed, Fig. 1a (2a) and c, 360-900 s. Figure 2b gives the calculated expanded height of the bed for the whole run and the heights above the distributor of individual thermocouples which reached the maximum temperature at the given point in the run. Note that after $\sim 360$ s the temperature plots intersected at $\sim 360 \mathrm{~s}$ and the temperature maximum moved under the bed's surface, fluctuations at thermocouples tc-2-tc-5, fell to the noise level, Fig. 2a-c respectively. With the mean temperature $>\sim 600^{\circ} \mathrm{C}$, explosions in bubbles occurred below the level of tc- 4 and when it rose to $>800^{\circ} \mathrm{C}$, after $\sim 600 \mathrm{~s}$ from ignition, temperature fluctuations at thermocouples tc- 6 and tc-7 fell, but the amplitude of those at the lower ones, tc- 3 and tc- 4 , increased. After $\sim 780 \mathrm{~s}$, at $>900^{\circ} \mathrm{C}$, fluctuations at tc- 3 and tc- $4, \sim 30 \mathrm{~mm}$ above the distributor decreased, while those at tc- 2 became stronger. This reflected the descent of the explosive reaction inside bubbles towards the distributor. At the end of the run, the gases ignited near tc- 2 or below it, when the bubbles had travelled $<20 \mathrm{~mm}$ from the distributor. Figure 3 shows, as a step function, the mean height at which the maximum in the vertical temperature profile was observed as the mean temperature changed, together with the calculated dynamic bed height and the height, derived from the kinetic model, at which the bubbles should explode. The model, using elementary reactions for hydrocarbons up to butane [22] has been described earlier [12]. The vertical, thin dashes lines show the trends in the position

Table 1 Variance of the fluctuations in the results from the thermocouples

\begin{tabular}{lclllll}
\hline $\begin{array}{l}\text { Symbol of } \\
\text { thermocouple }\end{array}$ & \multicolumn{2}{l}{ Time from ignition, $\mathrm{s}$} \\
\cline { 2 - 7 } & $200-360$ & $360-500$ & $500-600$ & $600-700$ & $700-800$ & $800-875$ \\
\hline tc-8 & 3.008 & 0.516 & 0.827 & 1.001 & 0.946 & 2.706 \\
tc-7 & 6.491 & 0.726 & 0.393 & 0.319 & 0.430 & 0.665 \\
tc-6 & 15.783 & 0.668 & 0.476 & 0.260 & 0.145 & 0.158 \\
tc-5 & 16.285 & 0.324 & 0.310 & 0.181 & 0.256 & 0.178 \\
tc-4 & 0.676 & 0.273 & 0.263 & 0.416 & 0.564 & 0.144 \\
tc-3 & 0.652 & 0.172 & 0.155 & 0.685 & 1.120 & 0.498 \\
tc-2 & 1.069 & 0.174 & 0.171 & 0.803 & 0.998 & 1.303 \\
\hline
\end{tabular}




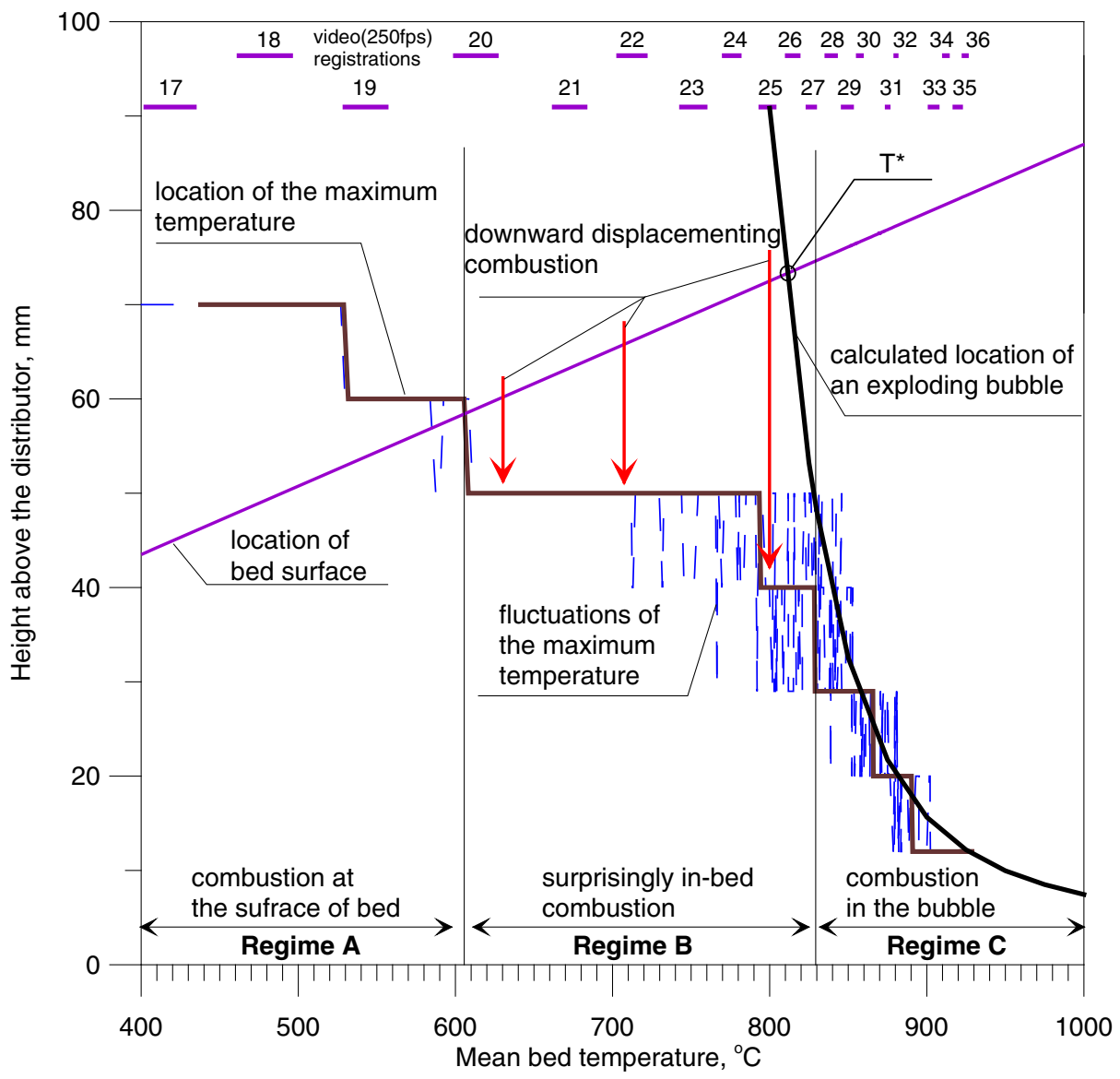

Fig. 3 The position of the region of reaction with respect to the bed's surface as a function of the mean temperature of the bed. Top of the diagram numbers of the video records and temperature ranges

of the temperature maximum, not the extent of the temperature fluctuations in its value. The theoretical curve for ignition inside bubbles and the line giving the bed's expanded height intersect at point $\mathrm{T}^{*}$. This should correspond to the transition between combustion above the bed and below its surface. Above this temperature, under regime $\mathrm{C}$, the position of the temperature maximum and the characteristic fluctuations registered by the thermocouples are consistent with intensive heat production lower in the bed and with further temperature rise near the distributor. Gases in the bubbles can then explode after delay times allowing them to travel $<20 \mathrm{~mm}$. Under regime B, with the bed at $605^{\circ} \mathrm{C}$ to $830^{\circ} \mathrm{C}$, Fig. 3, combustion occurs inside the bed as under regime $\mathrm{C}$, and is accompanied by short-term temperature fluctuations, although according to the model, at these temperatures the gases should burn above the bed. 


\subsection{The video results}

Film clips were recorded when the only light came from flames in the freeboard or the bed itself, as the mean temperature of the bed was raised to $600^{\circ} \mathrm{C}$ at $\sim 3.5 \mathrm{~K} / \mathrm{s}$ and then to $>800^{\circ} \mathrm{C}$ at $<1 \mathrm{~K} / \mathrm{s}$. The numbering and timing of the clips are given at the top of Fig. 3. Temperatures at the start and finish of each clip are given in Table 2. The clips (from SDV_17.MPG to SDV_36.MPG) are available as supplementary material with the electronic version of the paper. After careful analysis of the records and comparison between clips and fragments of them, frame sequences were selected to illustrate phenomena characterising the combustion process at different stages. The temperatures for the sequences were obtained assuming that during the recordings the mean temperature of the bed changed linearly with time. Sequences of events seen once only were ignored.

Figure 4 shows three sets of frames recorded as the sand was heating up, with flames above its surface. The lead wires for the thermocouple system can be seen in the freeboard. The wires, but not the thermocouples themselves, which are under the sand, can also be seen above the bed in Figs. 7, 8 and 9. The approximate position of the surface (dashed line) and the upper boundaries of the bubbles (dotted lines) are indicated. The camera could only see events near the wall of the reactor and so the surface here was the fragment of it next to the reactor wall facing the camera. With the sand radiating as a grey body, cooler material coming down near the walls showed as darker streaks, confusing the images. To bring out certain features, posttreatment of the images was sometimes necessary, such as changing the brightness and/or contrast, or resolving the colour images into red, green and blue.

Table 2 The mean temperature of the fluidised bed at the start and end of each video clip

\begin{tabular}{llr}
\hline No. of video clip & \multicolumn{2}{c}{ Mean bed temperature $\left[{ }^{\circ} \mathrm{C}\right]$} \\
\cline { 2 - 3 } & Start & End \\
\hline 17 & 403.1 & 433.8 \\
18 & 462.3 & 495.2 \\
19 & 529.7 & 555.9 \\
20 & 600.0 & 626.0 \\
21 & 662.9 & 682.6 \\
22 & 703.9 & 720.8 \\
23 & 743.9 & 758.9 \\
24 & 771.1 & 780.6 \\
25 & 794.4 & 802.8 \\
26 & 811.2 & 818.1 \\
27 & 824.4 & 828.6 \\
28 & 836.4 & 841.9 \\
29 & 846.8 & 852.1 \\
30 & 856.4 & 858.4 \\
31 & 874.8 & 875.4 \\
32 & 880.3 & 880.5 \\
33 & 902.1 & 906.6 \\
34 & 911.2 & 913.1 \\
35 & 917.9 & 921.5 \\
36 & 923.7 & 925.2 \\
\hline
\end{tabular}




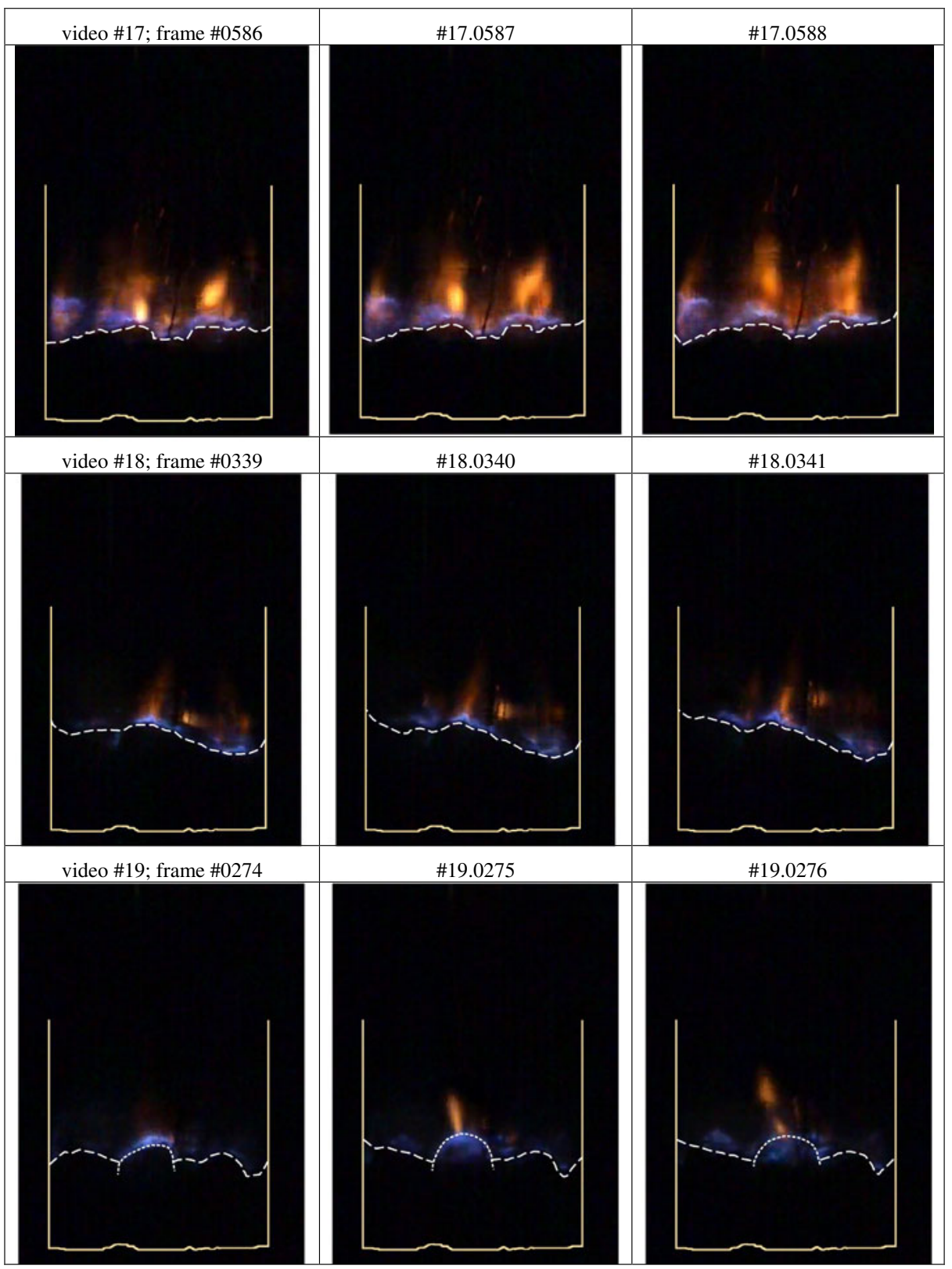

Fig. 4 Combustion over the fluidised bed's surface. Frames in sequences, in 3 rows: $\mathrm{T}_{\text {bed }}=410^{\circ} \mathrm{C}$ $($ top $) ; \mathrm{T}_{\text {bed }}=467^{\circ} \mathrm{C}($ middle $) ; \mathrm{T}_{\text {bed }}=533^{\circ} \mathrm{C}($ bottom $)$

The dynamic phenomena, with flames above the bed's surface or with periodic explosions under were to be reproducible — this was confirmed after examining many film sequences. From ignition to $\sim 600^{\circ} \mathrm{C}$ the gases burned above the bed, under Regime A and Fig. 4 shows 3 typical video sequences of three frames each. In 
sequence \#17, as the bed started warming up, blue flames hovered over its surface and long, candle-like yellow/orange flares rose above opening bubbles; in \#18 and \#19 the flares were weaker; in \#19 blue luminosity appeared inside a bubble, but flame jets were still there. The luminous flames could be due to particles of dust in the fluidising air and in cold sand, releasing contaminants as the sand became hot. Also, heat transfer was intense and the sand exerted a quenching effect, possibly leading to some soot formation [23]. Inspection of Fig. 4 (videos SDV_0017.MPG, SDV_0018.MPG and SDV_0019.MPG) confirmed earlier conclusion that at $\sim 200$ $360 \mathrm{~s}$, Fig. 2c, strong fluctuations in temperatures from the upper thermocouples, tc-5 to tc-8, were associated with flames hovering over the fluidised bed's surface. As successive thermocouples were engulfed, the fluctuations from them decreased, moving higher up as the bed expanded. When all thermocouples were inside the bed, the fluctuations settled down, to reach their minimum level after $\sim 450-600 \mathrm{~s}$, Fig. 2c.

Figure 5, a sequence of nine frames (from video SDV_0020.MPG), shows how combustion started moving into bubbles reaching the surface, without any flame jets above. At $617^{\circ} \mathrm{C}$, the induction period for self ignition inside gas bubbles was very considerably longer than the time required for them to reach the bed surface, but Fig. 5 shows the ignition of the gases inside a bubble arriving at the surface from the flame directly above it. At first, the lower boundary of the bubble could not be defined and the outline has been left open, frames \#20.1673-20.1676. Ignition inside the bubble, frame \#20.1676, lit it up, showing its lower boundary. Then it opened at the top, frames \#20.1678-20.1681, and its life cycle ended. This was typical, but bubbles could occasionally still reach the surface to release gases to burn for several milliseconds in a luminous flame (see also Fig. 1, frame D, in [10]).

When temperature in the reactor rose further, ignition in bubbles from surface flames above continued, but apparently the reaction could also travel from bubble to bubble. Figure 6 gives a sequence of 9 frames, obtained at $746^{\circ} \mathrm{C}$. The mixture then burned 40-50 $\mathrm{mm}$ above the distributor, when the kinetic model predicted self ignition $\sim 270 \mathrm{~mm}$ above the distributor (see Fig. 3), well clear of the bed surface at $\sim 70 \mathrm{~mm}$, but gave the correct results $>830^{\circ} \mathrm{C}$. In the sequence three bubbles are in the field of view, with blue flame luminosity above the middle one. The surface of the bed was then tilted towards the camera. Ignition in this bubble came from the flame above it (frame \#23.0416) and the travelled down, frames \#23.0418-23.0419. Due to thermal expansion of the gases and probably coalescence with an invisible bubble at the back, the bubble became very large and distorted - note the blue emission at the bottom. Ignition then occurred in the bubble on the left. As the reaction in the middle bubble was ending, it apparently moved to the bubble rising on the right and could be followed for $\sim 8 \mathrm{~ms}$, frames \#23.0421-23.0422. These observations were consistent with the temperature measurements. Figure 7 shows nine successive frames from video \#25, with the bed at $794^{\circ} \mathrm{C}$. In the first four frames, note the blue luminosity above the bulge in the surface of the bed over a large, irregular bubble. As before, the position of the bed's surface on the camera side is marked - the red glow came from material further away. The growth of the bubble lifted the bed's surface with the flame above (frames \#25.0023-25.0025), while on the left the surface subsided further. In frame \#25.0026, reaction moved into the bubble, swept down and the bubble opened. The blue emission indicated where the reaction was intense. The sequence thus shows that at $\sim 800^{\circ} \mathrm{C}$ bubbles can ignite and release heat between 50 and $25 \mathrm{~mm}$ above distributor, with flattening of the vertical temperature profile. This must be compared with Fig. 3, suggesting that ignition should begin to occur in 


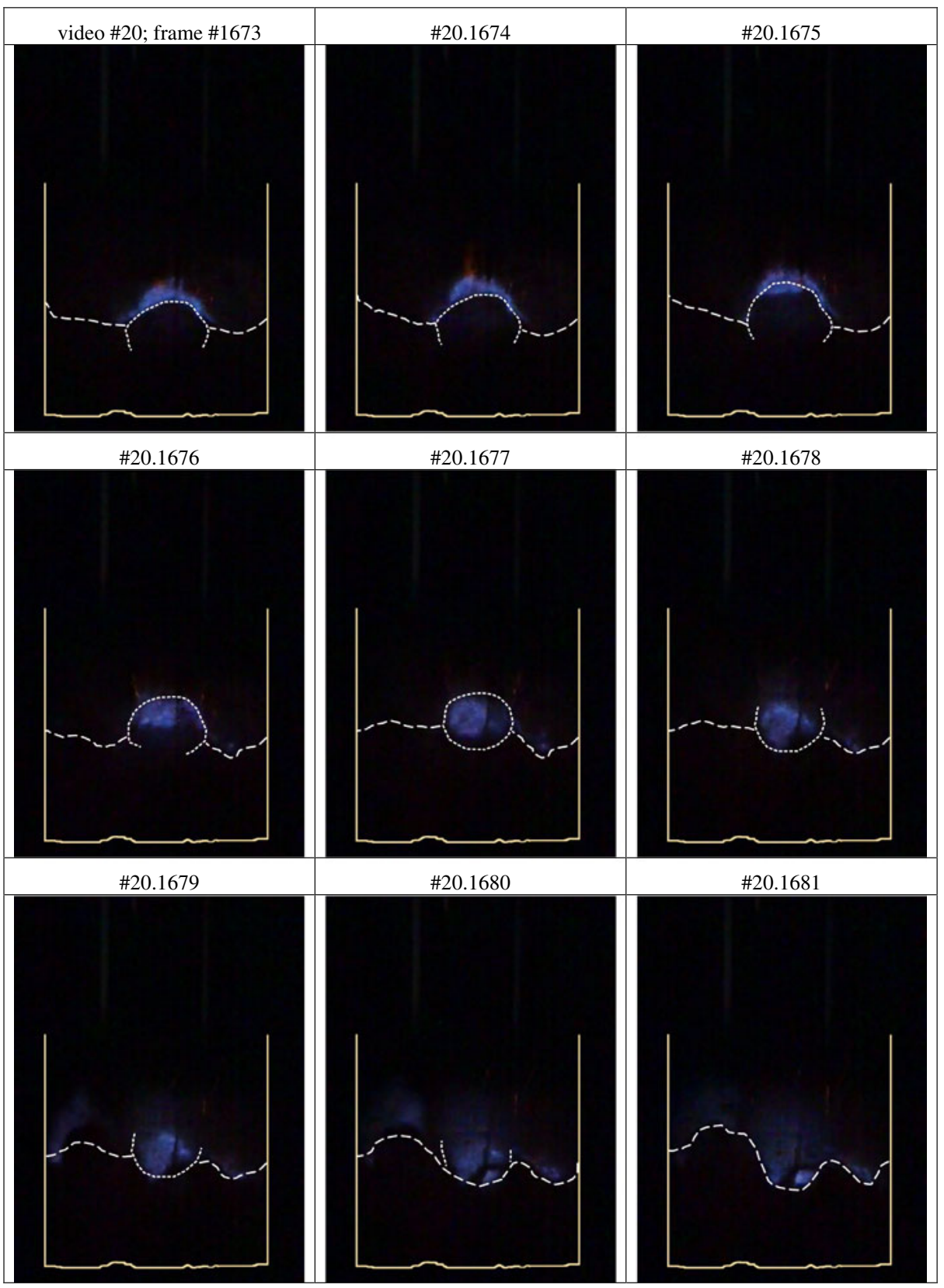

Fig. 5 Combustion in a bubble leaving the fluidised bed. A sequence of nine frames. $\mathrm{T}_{\text {bed }}=617^{\circ} \mathrm{C}$

the bed at the critical value $\mathrm{T}^{*}=\sim 815^{\circ} \mathrm{C}$, when the ignition delay becomes shorter than the residence time of the bubbles in the bed and the bed's mean surface should lie $\sim 70 \mathrm{~mm}$ above the distributor. Ignition of gas bubbles from the surface flames 


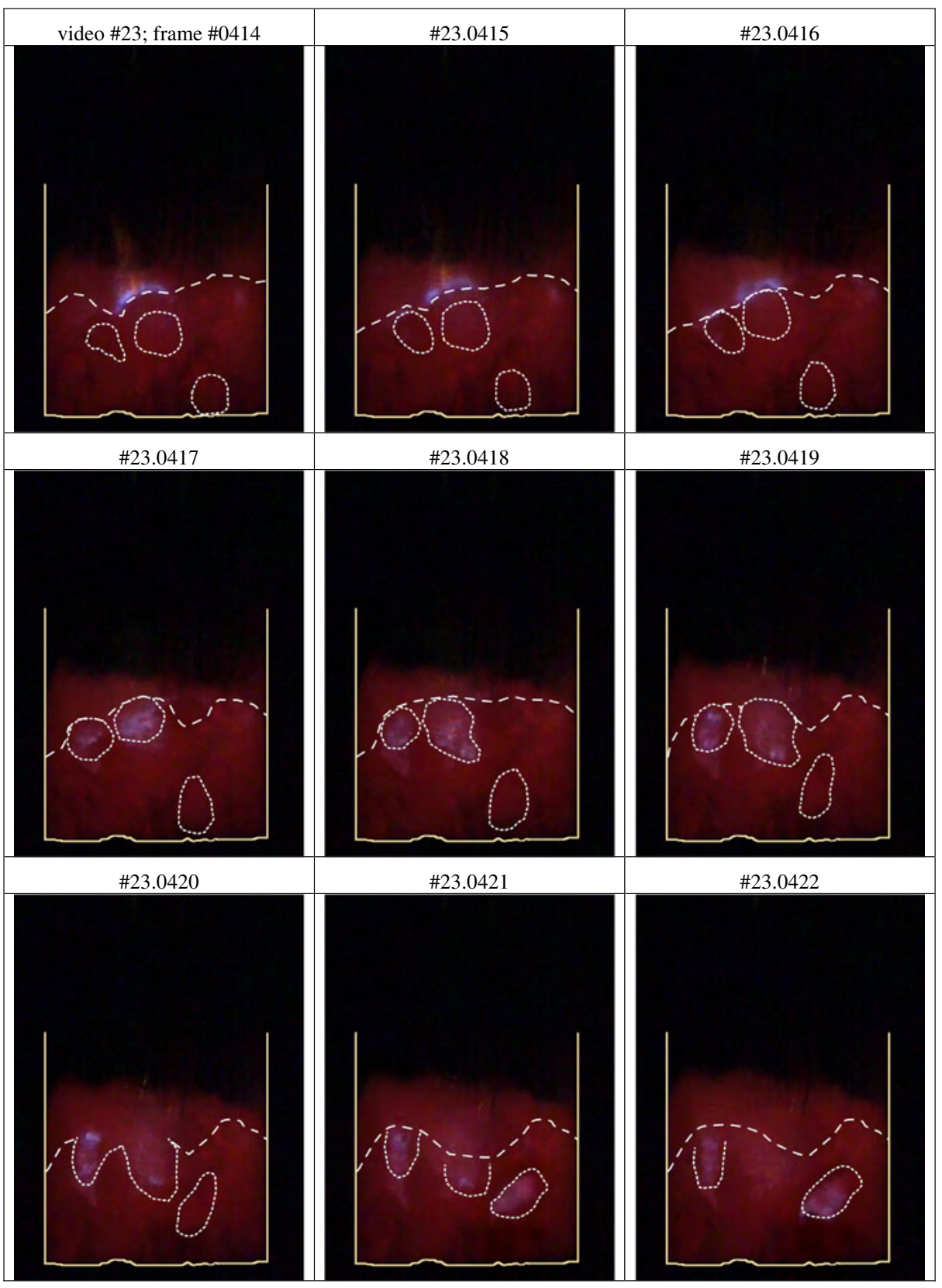

Fig. 6 Combustion in a bubble leaving the fluidised bed. A sequence of nine frames. $\mathrm{T}_{\text {bed }}=746^{\circ} \mathrm{C}$

brings the reaction down into the bed sooner than predicted by the kinetic model. This affects heat release and the vertical temperature profile.

Figure 8 is a sequence of nine frames from video $\# 28$, with the bed at $839^{\circ} \mathrm{C}$, just over the critical temperature illustrating transition from regime $\mathrm{B}$, reaction 


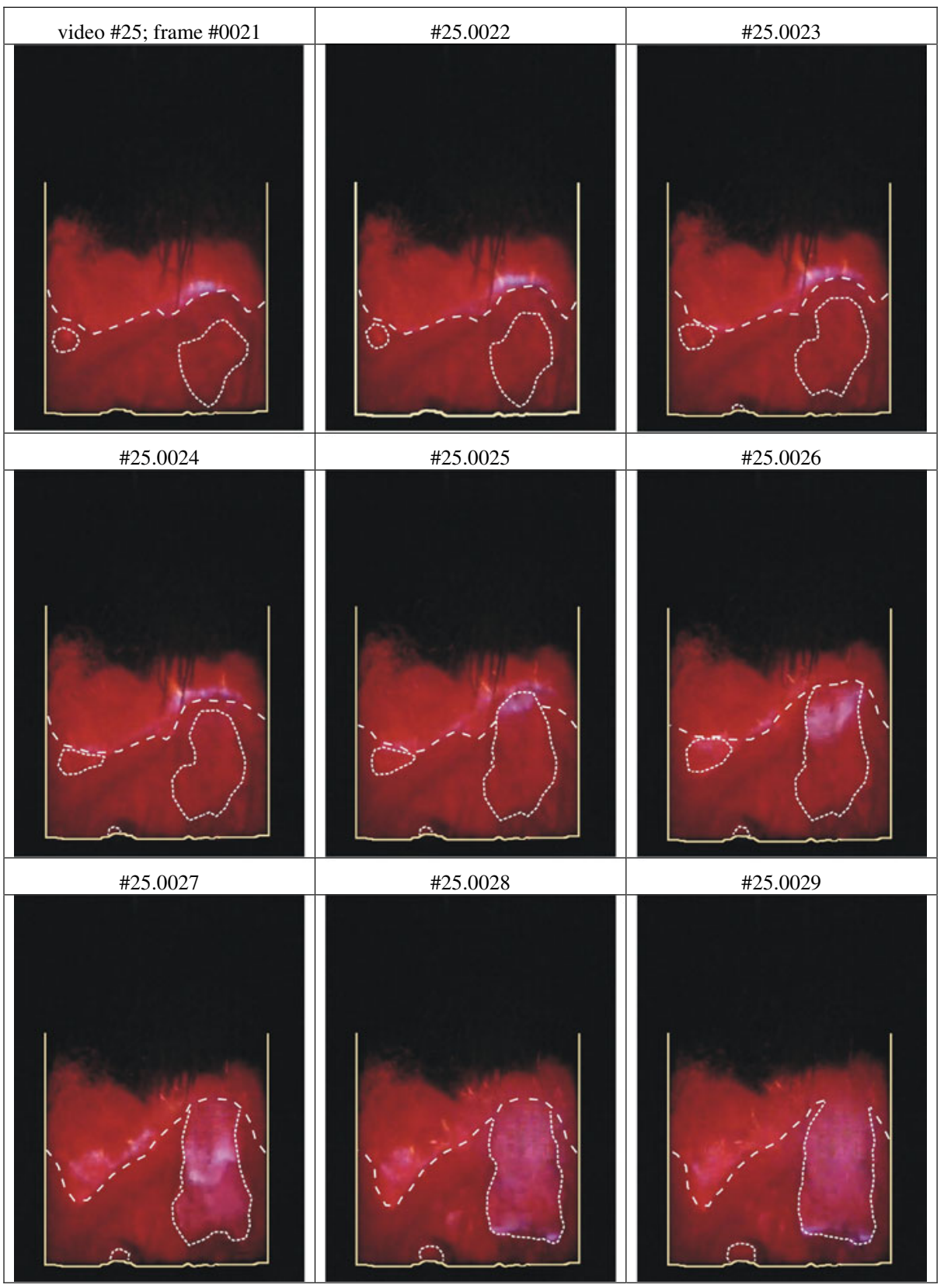

Fig. 7 Combustion inside the fluidized bed. A sequence of nine frames. $\mathrm{T}_{\text {bed }}=794^{\circ} \mathrm{C}$

in rising bubbles initiated from above, to regime $\mathrm{C}$, thermal ignition inside bubbles. Frames \#28.1372-28.1376, bottom left, show a small bubble igniting $\sim 11 \mathrm{~mm}$ above the distributor, almost level with thermocouple tc-2. At nearly the same time, on the right, combustion started inside a bubble $\sim 27 \mathrm{~mm}$ across, frames 


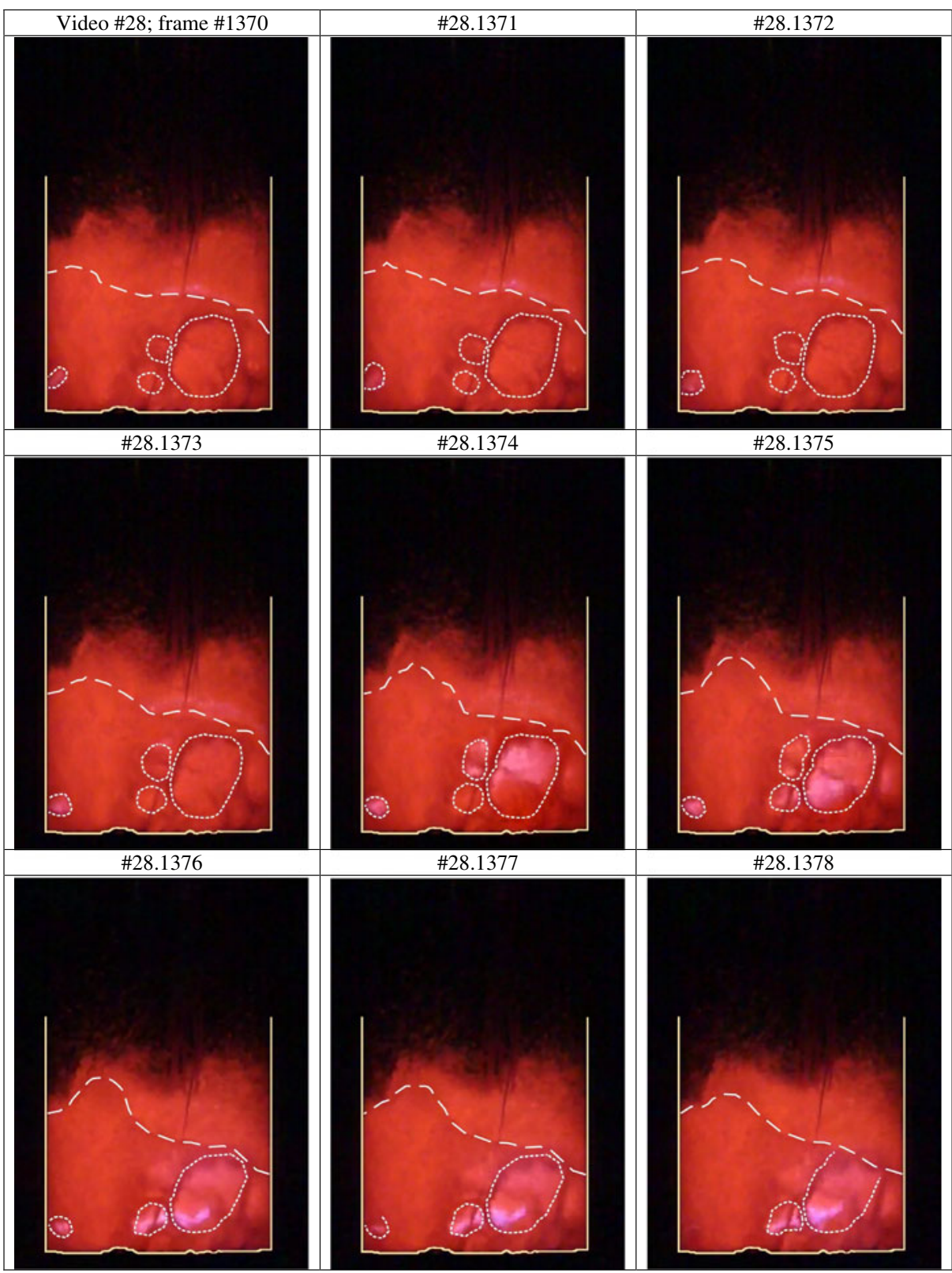

Fig. 8 Combustion inside the fluidized bed. A sequence of nine frames. $\mathrm{T}_{\text {bed }}=839^{\circ} \mathrm{C}$

\#28.1370-28.1372. The bubble's fate can be followed in frames \#28.1374-28.1378. The bubble was probably formed probably by the coalescence of one or more smaller ones; induced reaction in it could be favoured. The blue luminosity, with several centres, appeared to move down; this was also seen in Fig. 7. Finally, the small bubble on the left disappeared and the large one opened at the surface. Thus at $\sim 840^{\circ} \mathrm{C}$ 
ignition in bubbles can occur from above, leading to fluctuations at thermocouples tc-5 and tc- 6 , or thermally.

At over $850^{\circ} \mathrm{C}$ the gases exploded in many small bubbles lower down in the bed and as the temperature rose further, the explosions moved towards the distributor, in accordance with the kinetic model. The computed induction period was in good agreement with the height at which ignition occurred. The visual evidence is provided in Fig. 9, with three sequences, three frames each, at: $880^{\circ} \mathrm{C}$ (video \#32; frames \#32.2333-32.2335); $903^{\circ} \mathrm{C}$ (video \#33; frames \#33.0235-33.0237) and $921^{\circ} \mathrm{C}$ (video \#35; frames \#35.1983-35.1985). At $880^{\circ} \mathrm{C}$ a bubble ignited $\sim 25-27 \mathrm{~mm}$ above the distributor. About $4 \mathrm{~ms}$ later reaction started in the bubble below. This could have been induced by the proximity of the first or be due to thermal ignition. The third frame shows the end of the process. When the temperature exceeded $900^{\circ} \mathrm{C}$ the induction period became shorter still and the explosions occurred even lower down, video \#33; frames \#33.0235-33.0237. At $921^{\circ} \mathrm{C}$ the gases in most bubbles exploded just above the distributor, but even then some larger bubbles could ignite $\sim 20 \mathrm{~mm}$ above the distributor, video \#35; frames \#35.1983-35.1985. Note that in small bubbles the emission was brightest in the middle, while in the larger ones it was distributed over several areas. As mentioned above, this could result from bubble coalescence, but also partial quenching of the reaction in the new bubble, with more sand inside. Free radicals readily recombine on the surface of the sand particles, so reaction can only be possible inside bubbles, where the concentration of the particles is relatively low [16].

These observations confirmed that in a bubbling fluidised bed reactor a hydrocarbon (propane)-air mixture burns either above or under the bed's surface. Under regime $\mathrm{A}$, heat recuperation from flames above the bed is variable, since the gases in the fast bubbles are preheated passing through the sand, which is gradually heated by the flames. When regime B starts, two modes of ignition in the bed itself become possible, depending on the mean temperature and the ignition delay. When the residence time of bubbles in the bed is too short for thermal ignition to occur, the gases in a bubble can ignite from surface flames or from a neighbouring bubble. In both cases the presence of chemically active regions is signalled by the characteristic blue emission [10]. It is a matter of speculation whether the reaction is started by a sudden thermal impulse or the penetration of the bubble by active free radicals, produced in the flame or explosion in above equilibrium concentrations (the presence of free radicals under fluidised bed conditions is well documented [24-27]). Observations on the FBC combustion of hydrogen and kinetic modelling showed that premature ignition can occur if $\mathrm{H}$ atoms are effectively "injected" into the system at a catalytic surface close to the distributor [14]. It is also relevant that the ignition of propane is promoted by the presence of a solid catalyst, such as Ptcoated particles, on whose surface molecules can dissociate to produce free radicals [5]. In spite of the quenching effect of the sand on flame propagation, in the present work induced ignition was observed when the distance between the rising bubble and the flame above it or another bubble where ignition had already occurred was only a few millimetres. Since neither the upper surface nor the boundaries between bubbles are "solid" and the particles are in constant motion, channels through the boundary layers must open up quite frequently. Radicals might be able to pass through these, to initiate combustion. As the temperature rises and the ignition delay becomes comparable with the gas residence time, the importance of thermal ignition increases. 


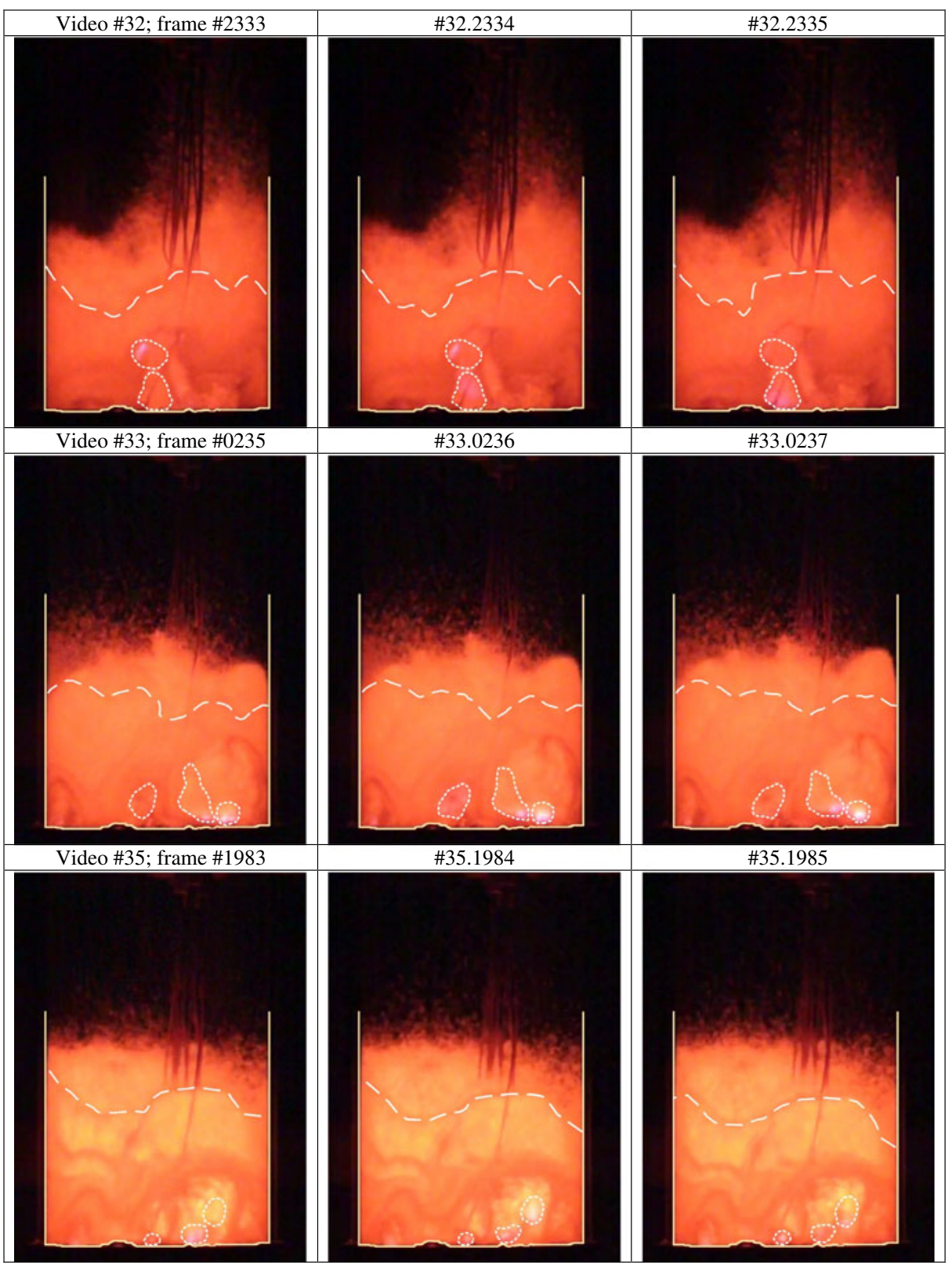

Fig. 9 Combustion inside the fluidized bed, three sequences of frames, $\mathrm{T}_{\text {bed }}=880,903$ and $921^{\circ} \mathrm{C}$, top, middle and bottom row respectively

Close to the critical temperature, thermal impulses should occur more frequently and with fewer side effects, as observed. Thus under regime $\mathrm{C}$, the situation is quite unlike that under regime $\mathrm{A}$, although both are stable. When regime $\mathrm{B}$ operates, the 
phenomena are more complex. The formation and coalescence of bubbles and the spread of reaction across thinning "curtains" of the emulsion phase are stochastic phenomena and the observations can be reproducible only in a statistical sense.

\subsection{Supporting evidence}

Additional semi-quantitative information was obtained by examining the composition of the gases in the freeboard. The concentration of $\mathrm{O}_{2}$ served as a measure of the overall combustion efficiency, while those of $\mathrm{CO}$ and VOCs were used to assess its quality. With no video recording, the screen around the reactor was lowered to limit radiative losses and the temperature rose to $>1000^{\circ} \mathrm{C}$. The screen was then raised and the reactor was cooled to $\sim 800^{\circ} \mathrm{C}$. It was reheated by reversing the procedure; then the fuel supply was cut off. Temperatures $>1000^{\circ} \mathrm{C}$ were reached twice, those in the range $\sim 800-1000^{\circ} \mathrm{C}$ occurred three times; passing through regime $\mathrm{A}$ and $\mathrm{B}$ to $\mathrm{C}$, back to $\mathrm{B}$ and then to $\mathrm{C}$ and extinction. Figure $10 \mathrm{a}$ gives the temperature records from thermocouples tc-2, tc-4, tc-6 and tc-8, Fig. 10b the dynamic height of the bed and the position of the temperature maximum in the bed under regimes $\mathrm{B}$ and $\mathrm{C}$. Records from all the thermocouples, Fig. 10c, fluctuate, similarly to those in Fig. 3 and the fluctuations depend only on where most heat is produced, not on whether the temperature is rising or falling.

The concentrations of $\mathrm{CO}$ and VOCs at different temperatures are shown in Fig. 11, together with the height at which maximum heat production occurred. As in Fig. 3, the computed height for ignition in rising bubbles is included. Note that the measured $\mathrm{CO}$ and VOCs concentrations were independent of the direction of the temperature change. Over the range $750-1000^{\circ} \mathrm{C}$ concentration were measured three times - the curves are superimposed.

The presence of $\mathrm{CO}$ and VOCs in the freeboard can only result from combustion reactions. Under regime A, when the bed receives heat only from flames above it, the concentrations of $\mathrm{CO}$ and VOCs rise together. This is probably because, although gas velocities increase, the flames move closer to the bed's surface (see Fig. 4). This enhances flame quenching by sand particles and promotes heat transfer to them. At this stage the freeboard is too cool for the oxidation reactions to go to completion outside the flames. At $\sim 550^{\circ} \mathrm{C}$ combustion starts in the bed under regime $\mathrm{B}$ and moves down as the temperature rises (see above). The concentrations of $\mathrm{CO}$ and VOCs change dramatically, but no longer together. That of $\mathrm{CO}$ rises to a peak at $\sim 740^{\circ} \mathrm{C}$ and then decreases steadily across the boundary between regimes $\mathrm{B}$ and $\mathrm{C}$, to below detection at $\sim 900^{\circ} \mathrm{C}$, regime $\mathrm{C}$. The concentration of VOCs passes through a maximum at $\sim 560-620^{\circ} \mathrm{C}$, well ahead of the $\mathrm{CO}$ peak and decays to below detection at $\sim 800^{\circ} \mathrm{C}$, still within regime $\mathrm{B}$. Regime $\mathrm{B}$ is thus marked by different behaviour of VOCs and of $\mathrm{CO}$, but the presence of one or both of them signals incomplete combustion. Under regime $\mathrm{C}$, when small gas bubbles ignite near the distributor, interactions between bubbles are not important and the kinetic model is obeyed both $\mathrm{CO}$ and VOCs disappear.

In contrast, under regime B the situation is affected by stochastic processes; ignition in bubbles from flames above or from neighbouring bubbles and bubble coalescence. Earlier results obtained from the same reactor are relevant here. Measured freeboard concentrations of $\mathrm{CO}, \mathrm{NO}, \mathrm{NO}_{2}$ and VOCs were always qualitatively similar for all hydrocarbons tested. Some results were unexpected. Under regime 


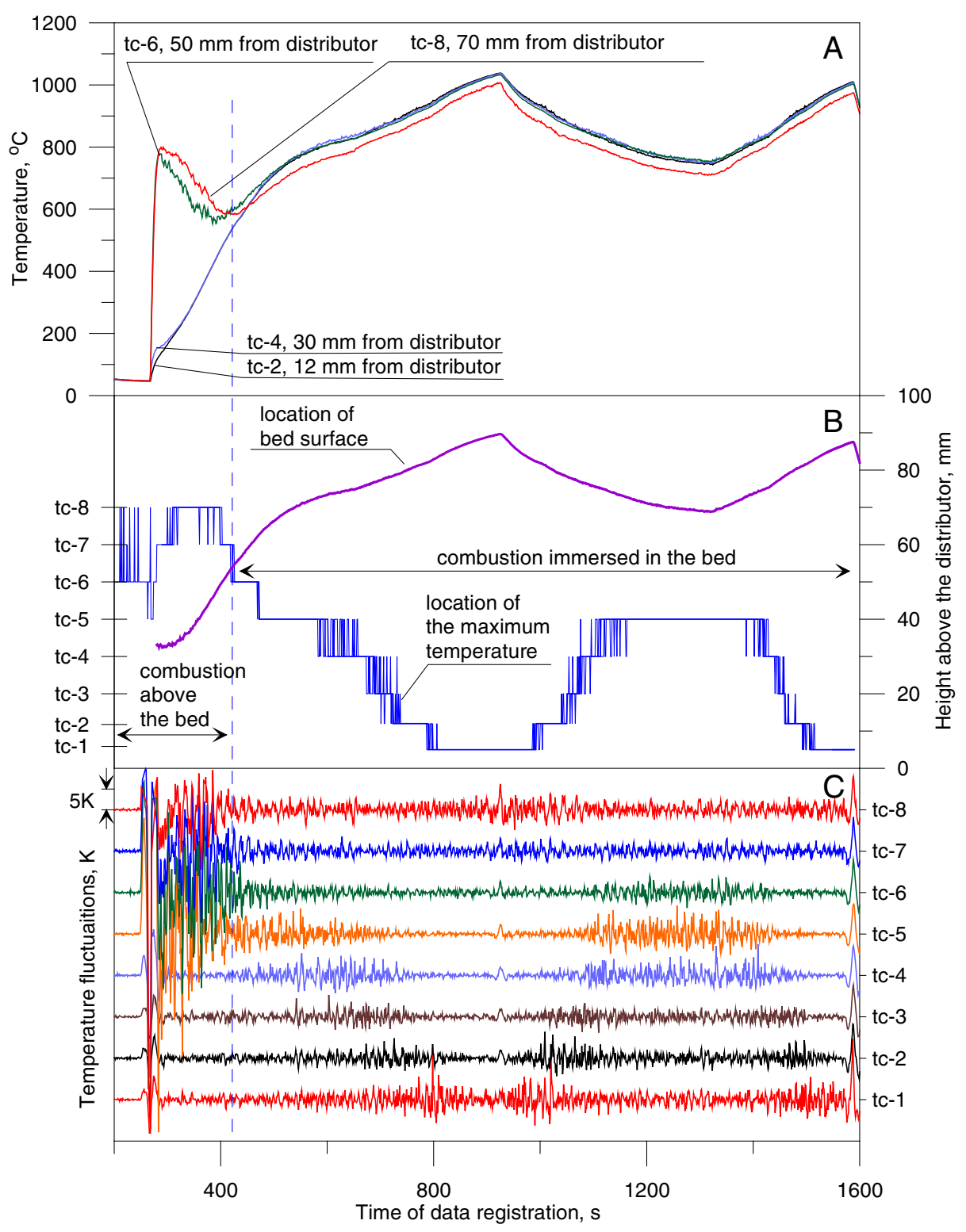

Fig. 10 Records from the control experiment as the reactor was taken through a temperature cycle. a Temperatures at the positions of selected thermocouples. b Changing position of the bed's surface and of the thermocouple giving highest temperature. c Fluctuations of temperature at different heights in the fluidised bed and above it

$\mathrm{B}$ the concentrations of $\mathrm{NO}, \mathrm{NO}_{2}$ and $\mathrm{CO}$ were linked and the under regime $\mathrm{C}$ the NO concentration fell with rising temperature [21, 28, 29].

Comparison with other work is difficult. van der Vaart burned stoichiometric propane-air in a bubbling bed $\left(\mathrm{U} / \mathrm{U}_{\mathrm{mf}}=\sim 2\right)$ at 750 and at $850^{\circ} \mathrm{C}$ and used a probe to 


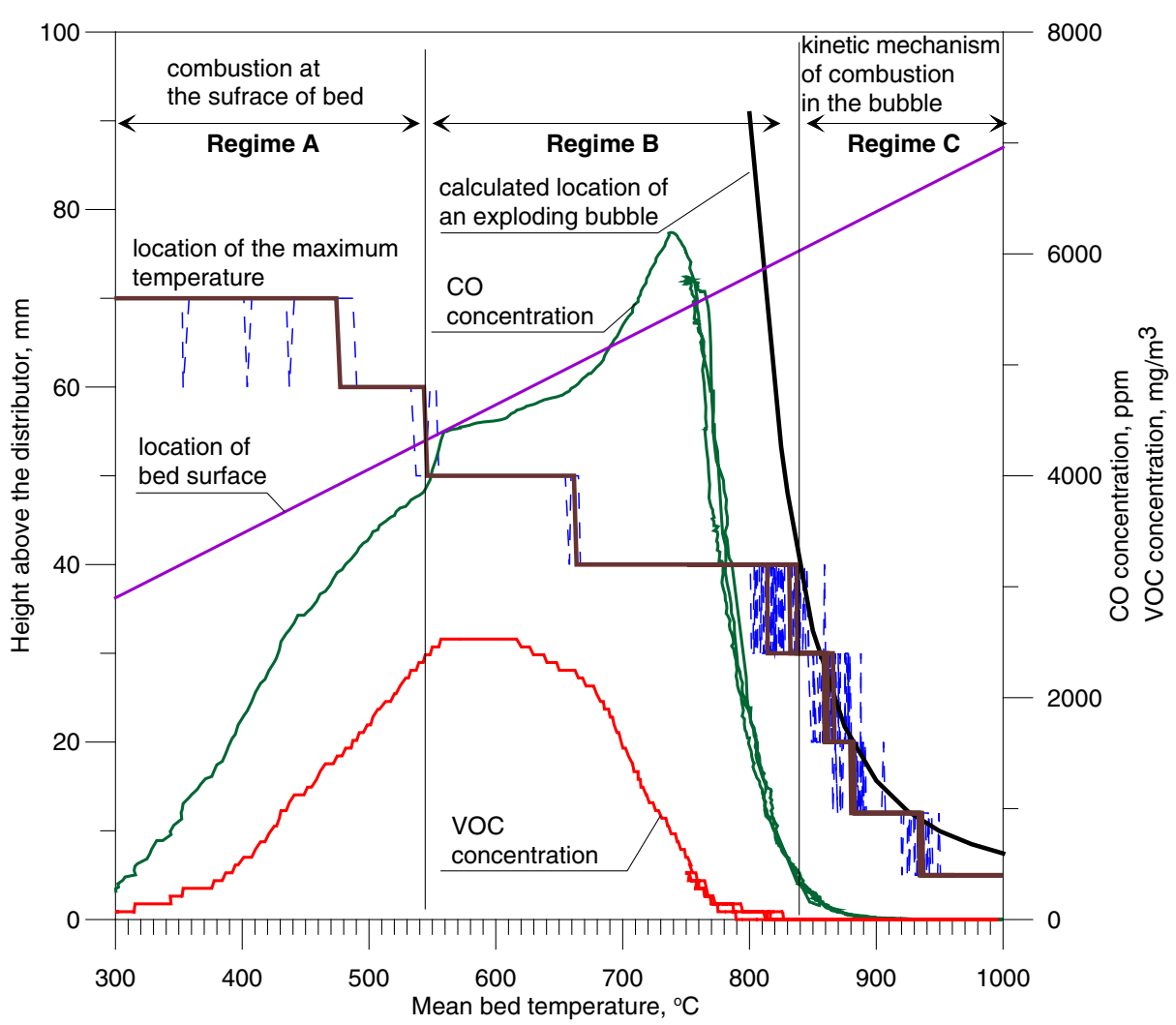

Fig. 11 The dependence of the concentrations of CO and VOCs on the mean temperature of the bed under combustion regimes $(\mathbf{a}-\mathbf{c})$

sample gases at different heights from the bed and the freeboard [30]. At $750^{\circ} \mathrm{C}$ the $\mathrm{CO}_{2}$ concentration was negligible at the bottom, rose near the bed's surface and was constant above. Hydrocarbon intermediates, $\mathrm{C}_{3} \mathrm{H}_{6}, \mathrm{C}_{2} \mathrm{H}_{4}$ and $\mathrm{CH}_{4}$, appeared near the bottom and peaked in the bed while $\mathrm{CO}$ reached a maximum higher up and did not fall off in the freeboard. At $850^{\circ} \mathrm{C}$ the concentrations of intermediates were much higher, with maxima in the lower half of the bed, falling towards the bed's surface, but $\mathrm{CO}$ persisted into the freeboard, where it decayed towards a constant level, while $\mathrm{CO}_{2}$ steadily rose in the bed and just above, to reach the same final level as at $750^{\circ} \mathrm{C}$. Our observations for regime B are consistent with [30] at $750^{\circ} \mathrm{C}$, but because the conditions were different, comparison could only be qualitative. Chadeesingh and Hayhurst [16] burned methane-air at different air/ $\mathrm{CH}_{4}$ ratios $\left(\mathrm{U} / \mathrm{U}_{\mathrm{mf}}=2-3.5\right.$ at $700^{\circ} \mathrm{C}$ ) and measured the concentrations of $\mathrm{CO}_{2}, \mathrm{CO}, \mathrm{CH}_{4}$ and $\mathrm{C}_{2} \mathrm{H}_{4}$ near the distributor as the temperature was raised from $450^{\circ} \mathrm{C}$ to $1125^{\circ} \mathrm{C}$ and lowered again until extinction at $\sim 600^{\circ} \mathrm{C}$. The experiment was basically similar to ours, except that the reactor was externally heated and fluidisation slower. With the air excess at $26 \%$, while the reactor was heated, the consumption of $\mathrm{CH}_{4}$ started slightly below $700^{\circ} \mathrm{C}$, slowly at first, then the $\mathrm{CO}$ concentration began to rise and went through a sharp maximum at $\sim 770^{\circ} \mathrm{C}$, while $\mathrm{CH}_{4}$ fell, then rose to a low peak and finally decayed, 
with no perturbation when the rate of heating was changed or the temperature reduced. As the $\mathrm{CO}$ concentration fell, that of $\mathrm{CO}_{2}$ rapidly rose to a steady level and stayed there, apparently unaffected by further temperature change. When the bed was cooled the prominent $\mathrm{CO}$ peak did nor reappear, but as the temperature fell from $950^{\circ} \mathrm{C}$ to $875^{\circ} \mathrm{C}$ the sand glowed brighter at the bottom and top of the bed, showing where the reaction occurred. This was reproducible. In all our earlier work, for combustion inside the bed results were practically the same, irrespective of the direction of temperature change. Also, for all fuels tested, except hydrogen [14], reaction was always confined to one region in the reactor. The difference could be due to differences in the experimental conditions; this makes comparisons harder [16], except under regime $\mathrm{C}$, with the temperature rising and ignition at the bottom of bed, when product concentrations low in the bed can be similar to those in the freeboard, i.e. when the situation is clear and there are no characteristic features to consider. However, these authors [16] raised a very important point. Combustion depends on branched chain chemical reaction. For hydrocarbons, as the temperature rises, there is a transition from the low temperature to the high temperature oxidation mechanism, from the dominance of the $\mathrm{HO}_{2}$ radical to that of $\mathrm{OH}$. Both free radicals are very important in the oxidation of hydrocarbons, particularly in the initial attack on hydrocarbon molecules,

$$
\begin{gathered}
\mathrm{C}_{\mathrm{x}} \mathrm{H}_{\mathrm{y}}+\mathrm{HO}_{2} \rightarrow \mathrm{C}_{\mathrm{x}} \mathrm{H}_{\mathrm{y}-1}+\mathrm{H}_{2} \mathrm{O}_{2} \\
\mathrm{C}_{\mathrm{x}} \mathrm{H}_{\mathrm{y}}+\mathrm{OH} \rightarrow \mathrm{C}_{\mathrm{x}} \mathrm{H}_{\mathrm{y}-1}+\mathrm{H}_{2} \mathrm{O}
\end{gathered}
$$

They also play the key role in the oxidation of $\mathrm{CO}$,

$$
\begin{gathered}
\mathrm{CO}+\mathrm{HO}_{2} \rightarrow \mathrm{CO}_{2}+\mathrm{OH} \\
\mathrm{CO}+\mathrm{OH} \rightarrow \mathrm{CO}_{2}+\mathrm{H}
\end{gathered}
$$

Reaction (4) dominates in most combustion systems [31]. Usually, if the CO concentration falls when the temperature rises, this can be ascribed to higher $\mathrm{OH}$ and the reaction rate constant increasing with temperature. Further clues on the effects of $\mathrm{HO}_{2}$ and $\mathrm{OH}$ radicals can be derived from the behaviour of $\mathrm{NO}$ and $\mathrm{NO}_{2}$, formed in small concentrations $(15-50 \mathrm{ppm})$ when hydrocarbon-air mixtures are burned in our bubbling fluidised bed reactor. It has been shown that $\mathrm{NO}$ is formed first (the mechanism is not directly relevant); the appearance of $\mathrm{NO}_{2}$ over a certain temperature range was attributed to efficient oxidation of NO in the reaction

$$
\mathrm{NO}+\mathrm{HO}_{2} \rightarrow \mathrm{NO}_{2}+\mathrm{OH}
$$

This only occurred at high $\mathrm{CO}$ concentrations [28]. In other work with the same reactor, with $\mathrm{CH}_{4}$ and LPG as fuels, $\mathrm{NO}$ and $\mathrm{NO}_{2}$ were in turn added to the system at high $\mathrm{CO}$, in concentrations well above the natural level of NO [29]. The observations are relevant to regime $\mathrm{B}$. The effect of $\mathrm{NO}$ or $\mathrm{NO}_{2}$ addition was the same, i.e. the same concentrations of $\mathrm{NO}$ and $\mathrm{NO}_{2}$ were found. Addition of $\mathrm{NO}$ at 100, 200 and 400 ppm resulted in increasing $\mathrm{NO}_{2}$ levels, while that of $\mathrm{CO}$ was progressively depressed, starting from the high temperature side. Hence the peak in the $\mathrm{CO}$ concentration observed under the B regime was flattened and as more NO was added, it moved to lower temperatures [29]. These results marked the temperature 
region in which the $\mathrm{HO}_{2}$ radical was important and indicated that a catalytic cycle was in operation, made up or reactions (4) and (5) together with

$$
\mathrm{H}+\mathrm{O}_{2}+\mathrm{M} \rightarrow \mathrm{HO}_{2}+\mathrm{M}
$$

$\mathrm{M}$ can be any stable molecule. These reactions add up to the oxidation of both $\mathrm{CO}$ and NO,

$$
\mathrm{CO}+\mathrm{NO}+\mathrm{O}_{2} \rightarrow \mathrm{CO}_{2}+\mathrm{NO}_{2}
$$

At higher temperatures the formation of $\mathrm{HO}_{2}$ in (6) had to compete with chain branching,

$$
\mathrm{H}+\mathrm{O}_{2} \rightarrow \mathrm{OH}+\mathrm{O}
$$

In combustion systems reaction (8) dominates at temperatures above $\sim 800^{\circ} \mathrm{C}$. Transition from the low temperature mechanism of hydrocarbon oxidation when $\mathrm{HO}_{2}$ is important to the high temperature mechanism when $\mathrm{OH}$ dominates occurs when the chain branching reaction (8) becomes faster than the formation of $\mathrm{HO}_{2}$ in reaction (6) [31]. When more $\mathrm{OH}$ appears, the oxidation of $\mathrm{CO}$ becomes faster but formation of $\mathrm{NO}_{2}$ slows down while its thermal decomposition accelerates, so that it practically disappears from the system. On the low temperature side the effect of $\mathrm{NO}$ on $\mathrm{CO}$ is much weaker. Combustion is also strongly quenched when the reaction first moves from flames over the bed to bubbles arriving at the surface. This is why the concentrations of $\mathrm{CO}$ and of VOC's rise over part of regime $\mathrm{B}$.

Under regime B the conditions are specific. "Premature" ignition in bubbles can occur from the surface or from neighbouring bubbles, but the sand particles exert a strong quenching effect. The temperature is low and the chemistry is dominated by the $\mathrm{HO}_{2}$ radical, less reactive than $\mathrm{H}$ or $\mathrm{OH}$ (except in oxidising $\mathrm{NO}$ ). Hence the concentrations of $\mathrm{CO}$ and VOCs are high. As the temperature rises, $\mathrm{HO}_{2}$ can initiate the oxidation of VOC molecules and oxidise NO, but the oxidation of $\mathrm{CO}$ is slow, so its concentration rises, passing through a maximum when reaction (8) overtakes (6) to produce $\mathrm{OH}$. The oxidation of $\mathrm{CO}$ accelerates, generating more $\mathrm{OH}$ via reactions (8) and (4). Addition of NO can promote oxidation of CO at lower temperatures via process (7), provided reaction (5) is faster than (8). Thus the oxidation of NO marks the temperature region when the $\mathrm{HO}_{2}$ radical dominates. The change from $\mathrm{HO}_{2}$ to $\mathrm{OH}$ dominance occurs within the temperature range of regime $\mathrm{B}$.

Mathematical modelling of regime $\mathrm{B}$ has not yet been attempted, but the dynamic and physicochemical effects involved have been identified. This is the first step for building a model, but to put it on a firm basis more suitably designed experiments are needed on interactions between bubble dynamics and chemical reactions in bubbling fluidised beds.

\section{Summary and Conclusions}

In a bubbling fluidised bed reactor with a bed of quartz sand, a hydrocarbon-air mixture can burn under one of three regimes. With no external heating all heat comes from the reaction. After ignition at ambient temperature the bed is gradually heats up. First, under the dynamic regime A, flames hover above the surface of the bed and gradually heat the sand. When the bed is uniformly hot, the mixture 
explodes in bubbles close to the distributor. This is the steady state regime C. Both situations are fully accounted for; the present results confirmed earlier conclusions, based on acoustic, pressure and temperature measurements, kinetic modelling and visual observations when the mean temperature of the bed was changed.

Between regimes $\mathrm{A}$ and $\mathrm{C}$, as the bed's mean temperature rises, combustion gradually moves from the surface to just above the distributor. For propane, with $40 \%$ air excess, this is occurs between $\sim 600$ and $\sim 830^{\circ} \mathrm{C}$. The gases ignite inside bubbles, but after delay times much shorter than predicted by the kinetic model - this is regime B. Fast video recording of the phenomena occurring under the three regimes enabled us to capture images of bubbles moving through the bed, from ignition of the gases to bubbles bursting at the bed's surface. It has been shown that the "premature" explosions occur in bubbles approaching the surface as a result of ignition from flames above the bed's surface or due to the transfer of reaction between neighbouring bubbles. In both cases the reaction appears to be able to cross a thin, moving curtain of moving sand particles. The sand particles exert a quenching effect, but enough free radicals can presumably pass through the sand curtain to initiate reaction. Bubble coalescence also plays a part. Under regime $\mathrm{B}$, the concentrations of $\mathrm{CO}$ and VOCs above the bed are high and undergo characteristic changes, ascribed to the transition from kinetics dominated by the $\mathrm{HO}_{2}$ radical to that when $\mathrm{OH}$ is important. The character of the regime is determined by the interaction of dynamic phenomena occurring in a bubbling fluidised bed with the physicochemical combustion process, governed by branching chain reactions in which free radicals play a key role. Quenching of gas phase reactions by solid particles and, as regime $\mathrm{C}$ is approached, change in the combustion mechanism from the dominance of the $\mathrm{HO}_{2}$ radical to that of $\mathrm{OH}$ must also be considered.

Open Access This article is distributed under the terms of the Creative Commons Attribution Noncommercial License which permits any noncommercial use, distribution, and reproduction in any medium, provided the original author(s) and source are credited.

\section{References}

1. van der Vaart, D.R., Davidson, J.F.: In: Proceedings of the 5th Engineering Foundation Conference on Fluidization, pp. 539-546 (1986)

2. van der Vaart, D.R.: Freeboard ignition of premixed hydrocarbon gas in a fluidized bed. Fuel 67, 1003-1007 (1988)

3. Hesketh, R.P., Davidson, J.F.: Combustion of methane and propane in an incipiently fluidised bed. Combust. Flame 85, 449-467 (1991)

4. Dennis, J.S., Hayhurst, A.N., Mackley, I.G.: The ignition and combustion of propane/air mixtures in a fluidised bed. Proc. Combust. Inst. 19, 1205-1212 (1982)

5. Hayhurst, A.N., John, J.J., Wazacz, R.J.: The combustion of propane and air as catalysed by platinum in a fluidised bed of hot sand. Proc. Combust. Inst. 27, 3111-3118 (1998)

6. Hayhurst, A.N.: Does carbon monoxide burn inside a fluidized bed? A new model for the combustion of coal char particles in fluidized beds. Combust. Flame 85, 155-168 (1991)

7. Zukowski, W.: Acoustic effects during the combustion of gaseous fuels in a bubbling fluidized bed. Combust. Flame 117, 629-635 (1999)

8. Zukowski, W.: An acoustic method of studying sequential explosions during gas combustion in bubbling fluidised beds. Combust. Flame 125, 1075-1082 (2001)

9. Zukowski, W.: The pressure pulses generated by the combustion of natural gas in bubbling fluidised beds. Combust. Flame 130, 15-26 (2002) 
10. Bulewicz, E.M., Żukowski, W., Kandefer, S., Pilawska, M.: Flame flashes when bubbles explode during the combustion of gaseous mixtures in a bubbling fluidised bed. Combust. Flame 132, 319-327 (2003)

11. Gaydon, A.G.: The spectroscopy of flames, 3rd edn. Chapman and Hall, London (1974)

12. Zukowski, W.: A simple model for the explosive combustion of premixed natural gas with air in a bubbling fluidised bed of inert sand. Combust. Flame 134, 399-409 (2003)

13. Zukowski, W.: Methane and ethane combustion in an inert fluidised bed. In: Proceedings of the 18th International Conference on Fluidized Bed Combustion. ASME, Toronto, Canada, Paper: FBC2005-78100 (2005)

14. Baron, J., Bulewicz, E.M., Kandefer, S., Pilawska, M.,Żukowski, W., Hayhurst, A.N.: Combustion of hydrogen in a bubbling fluidized bed. Combust. Flame 156, 975-984 (2009)

15. Żukowski, W., Baron, J., Bulewicz, E.M., Kowarska, B.: An optical method of measuring the temperature in a fluidised bed combustor. Combust. Flame 156, 1445-1452 (2009)

16. Chadeesingh, D.R., Hayhurst, A.N.: The combustion of mixtures of methane and air in bubbling fluidized beds of hot sand. In: Winter, F. (ed.) Proceedings of the 19th International Conference on Fluidized Bed Combustion, chapter: C - Fundamentals R\&D. Vienna, Austria (2006)

17. Müller, C.R., Rees, A.C., Mantle, M.D., Sederman, A.J., Davidson, J.F., Dennis, J.S., Fennell, P.S., Gladden, L.F., Hayhurst, A.N.: Investigation of the formation of jets in a three-dimensional gas-fluidized bed using Magnetic Resonance Imaging. In: Proceedings of the AIChE Spring Annual Meeting - 5th World Congress on Particle Technology, p. 11. Orlando, FL, USA (2006)

18. Rees, A.C., Davidson, J.F., Dennis, J.S., Fennell, P.S., Gladden, L.F., Hayhurst, A.N., Mantle, M.D., Müller, C.R., Sederman, A.J.: The nature of the flow just above the perforated plate distributor of a gas-fluidised bed, as imaged using magnetic resonance. Chem. Eng. Sci. 61, 60026015 (2006)

19. Fennell, P.S., Davidson, J.F., Dennis, J.S., Gladden, L.F., Hayhurst, A.N., Mantle, M.D., Müller, C.R., Rees, A.C., Scott, S.A., Sederman, A.J.: A study of the mixing of solids in gas-fluidized beds, using ultra-fast MRI. Chem. Eng. Sci. 60, 2085-2088 (2005)

20. Wen, C.Y., Yu, Y.A.: A generalised method for predicting the minimum fluidisation velocity. AIChE J. 12(3), 610 (1966)

21. Baron, J., Bulewicz, E.M.,Zukowski, W., Kandefer, S., Pilawska, M.: Combustion of hydrocarbon fuels in a bubbling fluidised bed. Combust. Flame 128, 410-421 (2002)

22. Marinov, N.M., Pitz, W.J., Westbrook, C.K., Vincitore, A.M., Castaldi, M.J., Senkan, S.M.: Aromatic and polycyclic aromatic hydrocarbon formation in a laminar premixed n-butane flame. Combust. Flame 114, 192-213 (1998)

23. Gaydon, A.G., Wolhard, H.G.: Flames, 3rd edn. Chapmann \& Hall, London (1970)

24. Bulewicz, E.M., Janicka, E., Kandefer, S.: Halogen Inhibition of CO Oxidation during the Combustion of Coal in a Fluidized Bed. In: Maneker, A.M. (ed.) Proceedings of the 10th International Conference on Fluidized Bed Combustion, pp. 163-168. ASME, New York (1989)

25. Anthony, E.J., Bulewicz, E.M., Preto, F.: The effect of halogens on FBC systems. In: Rubow, L. (ed.) Proceedings of the 12th International Conference on Fluidized Bed Combustion, pp. 41-52. ASME, New York (1993)

26. Winter, F., Wartha, C., Hofbauer, H.: The relative importance of radicals on the $\mathrm{N}_{2} \mathrm{O}$, and NO formation and destruction paths in a quartz CFBC. In: Preto, F. (ed.) Proceedings of the 14th International Conference on Fluidized Bed Combustion, pp. 1131-1137. ASME, New York (1997)

27. Bulewicz, E.M.: Free radicals. In: Grace, J.R., Zhu, J., de Lasa, H. (eds.) Proceedings of the 7th International Conference on CFBC, pp. 13-26. Ottawa, Ontario, Canada (2002)

28. Bulewicz, E.M., Pilawska, M., Kandefer, S.: Natural gas combustion in a bed of sand. In: Preto, F. (ed.) Proceedings of the 14th International Conference on Fluidized Bed Combustion, pp. 1103-1110. ASME, New York (1997)

29. Kandefer, S., Pilawska, M., Środa, B.: Behaviour of nitrogen oxides during the combustion of hydrocarbons in a bubbling fluidized bed combustor. In: Proceedings of the 5th Conference on Technologies and Combustion for a Clean Environment, pp. 295-303. Lisbon, Portugal (1999)

30. van der Vaart, D.R.: The chemistry of premixed hydrocarbon/air combustion in a fluidized bed. Combust. Flame 71, 35-39 (1988)

31. Griffiths, J.F., Barnard, J.A.: Flame and combustion, 3rd edn. Blackie, London (1995) 